\title{
Comparison of the efficacy of nickel-titanium rotary systems with or without the retreatment instruments in the removal of gutta-percha in the apical third
}

\author{
Flávio Rodrigues Ferreira Alves ${ }^{1 *}$, Thiago Oliveira Ribeiro ${ }^{1}$, Jaime Omar Moreno ${ }^{1,2}$ and Hélio Pereira Lopes ${ }^{1}$
}

\begin{abstract}
Background: The purpose of this study was to compare the efficacy of nickel-titanium rotary systems with or without the retreatment instruments in the removal of gutta-percha from the apical third.

Methods: The systems compared were as follows: ProTaper Universal (PT), ProTaper Universal Retreatment (PTr), Mtwo (M2) and Mtwo Retreatment (M2r). Sixty extracted mandibular incisors were treated with a crown-down technique and filled with gutta-percha and sealer. The apical diameter was standardized in $0.30 \mathrm{~mm}, 1 \mathrm{~mm}$ from the apex. The teeth were distributed into 4 experimental groups: PT, PTr, M2 and M2r. In PTr and M2r groups, filling materials were removed by PTr/M2r followed by root canals preparation up to a PT F4/M2 40; in groups PT/M2, the filling materials were removed and the root canals were prepared by PT up to a PT F4/M2 up to a M2 40. The roots were split and photomicrographing. The percentage of clean area in the apical $5 \mathrm{~mm}$ was calculated using software. Data were analyzed with the Kruskal-Wallis test.

Results: Remaining material was found in all hemisections and there was no statistically significant difference between the groups $(p=0.09)$. Considering the surface of the canal walls of all teeth, the mean of the percentage of clean area was $54 \%$.

Conclusions: Considering the applied methodology, remaining filling material was found in all hemisections, regardless of the retreatment technique and PT or M2 were as effective as PTr/PT or M2r/M2.
\end{abstract}

Keywords: Gutta-percha removal, Mtwo, ProTaper Universal, Root canal retreatment, Rotary NiTi instruments

\section{Background}

The main objective of endodontic retreatment is the same as any other form of treatment, to restore or prevent the health of the periapical tissues. Therefore, it is necessary to remove the filling material from root canals, to clean, to shape and to re-fill them. Rotary instrumentation systems have been applied in retreatment, not only for the reinstrumentation of root canals, but also for removal of filling material [1].

\footnotetext{
* Correspondence: flavioferreiraalves@gmail.com

'Department of Endodontics, Faculty of Dentistry, Estácio de Sá University, Av. Alfredo Baltazar da Silveira, 580/cobertura, Recreio dos Bandeirantes, Rio de Janeiro, RJ 22790-710, Brazil

Full list of author information is available at the end of the article
}

Some established instrumentation systems, such as ProTaper (PT) and Mtwo (M2), have recently introduced specific instruments for removing filling materials during retreatment. ProTaper Universal Retreatment System (PTr) has three instruments, D1-30/0.09, D2-25/0.08, and D3-20/0.07 and Mtwo Retreatment (M2r) has two instruments, R1-15/0.05 and R2-25/0.05. Few studies have compared the effectiveness of these retreatment systems. Bramante et al. [2] compared the removal of gutta-percha and zinc oxide and eugenol-based sealer provided by $\mathrm{PTr}, \mathrm{M} 2 \mathrm{r}$ and Hedström files by measuring of remaining material areas observed on a stereomicroscope $(\times 12.5)$. Mtwo Retreatment files were less effective, leaving a significantly higher amount of filling material compared to the other instruments. PTr and hand files did not differ 
in the cleaning ability. Somma et al. [3] comparing the cleaning provided by the same instruments, founded that manual removal of different filling materials was more effective than rotary systems. Using a logistic regression model, the authors showed that the apical third of the root canal had the greatest impact on the score values. Marfisi et al. [4] found no significant differences in the area of remaining material, between PTr and M2r in roots filled with gutta-percha or resilon.

The removal of filling material simultaneously with the instrumentation has also been used for guttapercha removal, using only the rotary instrumentation systems (and not the retreatment instruments) [5-7]. Tasdemir et al. [7] compared ProTaper, Mtwo, Hedström files and R-Endo (an exclusive system for retreatment) in removing gutta-percha. The teeth used in the study were rendered transparent and the area of remaining filling material was measured using computer software. PT was significantly more effective than M2 in cleaning. The other comparisons between the techniques were not statistically significant.

It is not yet established in literature if specific instruments for filling removal are essential for retreatment with $\mathrm{NiTi}$ rotary systems. Therefore, this in vitro study compared ProTaper and Mtwo efficacy, preceded or not by the retreatment instruments, in the removal of filling material from the apical third of root canals.

\section{Methods}

Sixty human extracted mandibular incisors with completely developed apices were provided by Tooth Bank of Estácio de Sá University. The reasons for extraction were not related to this study, and the ethics committee of the Estácio de Sá University approved the research protocol (process number 0133.0.308.000-10). Bucco-lingual and mesio-distal radiographs were taken to confirm the existence of a single straight canal. The coronal access cavity was prepared using high-speed diamond burs under water spray.

\section{Initial preparation}

The root canals were prepared with a crown-down instrumentation approach using the principles of the alternated rotary motions technique [8], through the following steps: 1 . Canal negotiation and establishment of patency with \#10-\#20 stainless steel K-files (Maillefer, Ballaigues, VD, Switzerland); 2. Gates-Glidden burs (Maillefer, Ballaigues, VD, Switzerland) in the coronal two-thirds; 3. Working length (WL) determination at $1 \mathrm{~mm}$ from the apical foramen introducing a K-file \#10 into the canal until it was visible at the foramen; 4 . Hand stainless steel K-files preparation in the apical third up to a \#30 mm in WL; 5. Step back with stainless steel K-files increasing the size of the instruments and backing up the length (in steps of $1 \mathrm{~mm} ; 3-5$ step-backs were sufficient to complete the preparation). During the preparation, abundant and frequent irrigation with $2.5 \% \mathrm{NaOCl}$ (usually 1-2 $\mathrm{mL}$ after each file size) were performed. After irrigation, apical patency was verified by introducing a \#10-\#20 K-file in the canal until its tip was visualized at the apical foramen. Upon completion of chemomechanical preparation, smear layer was removed with a total of $5 \mathrm{ml}$ of 17\% EDTA (Biodinâmica, Ibiporã, PR, Brazil) for 3 min (renewing after each minute) and then the root canal was irrigated with $2.5 \% \mathrm{NaOCl}$ again.

The teeth were dried with absorbent paper point and subsequently filled with laterally compacted gutta-percha, using a standard master cone size 30 (Dentsply, Petrópolis, RJ, Brazil), which was introduced $1 \mathrm{~mm}$ shorter of the apex, and fill canal sealer (TECHNEW, Rio de Janeiro, Brazil), a zinc oxide and eugenol-based sealer. The quality of the filling was checked through bucco-lingual and mesio-distal radiographs. The teeth were then stored in $100 \%$ humidity at $37^{\circ} \mathrm{C}$ for 14 days to allow for the sealer to set.

The teeth were transversely sectioned with a double-sided diamond disc at $15 \mathrm{~mm}$ from the apex. The purpose of this step was to establish a standard length.

The roots were randomly divided into 4 groups of 15 each as follows; group PTr, filling material was removed with PTr (Dentsply Maillefer, Ballaigues, VD, Switzerland) followed by preparation with the PT system (Dentsply Maillefer, Ballaigues, VD, Switzerland), up to F4-40/ 0.06-0.05-0.04-0.03; group PT, filling removal and reinstrumentation with $\mathrm{PT}$ system up to $\mathrm{F} 4$; group M2r, filling removal with M2r (VDW, Munich, BY, Germany) followed by preparation with M2 system (VDW, Munich, BY, Germany) up to F4-40/0.04; and group M2, filling removal and reinstrumentation with M2 system, up to file F4-40/0.04.

\section{Filling removal and reinstrumentation}

The filling material was removed coronally to the extent of $2 \mathrm{~mm}$ deep by using a cylindrical diamond bur number 50 (KG Sorensen, Cotia, SP, Brazil). These cavities were filled with one drop of eucalyptol solvent (Biodinâmica, Ibiporã, PR, Brazil) using an insulin syringe, which was left in place for $3 \mathrm{~min}$ before starting filling removal.

The torque for all rotary instruments was 1.0 N.cm. The speed for retreatment instruments was $700 \mathrm{rpm}$ and $300 \mathrm{rpm}$ for the PT and M2. The movement applied to all rotary instruments was the enlargement with continuous rotation. After filling removal (PTr and M2r groups), the root canals were irrigated with $2 \mathrm{~mL}$ of $2.5 \% \mathrm{NaOCl}$ to remove the debris formed. During the reinstrumentation (all groups), a pattern of irrigation with $2 \mathrm{~mL}$ of $2.5 \%$ $\mathrm{NaOCl}$ at each change of files was established. A hypodermic needle with $0.55 \mathrm{~mm}$ of diameter was used to allow penetration to the middle third of the roots. WL 
adopted for both filling removal and reinstrumentation was $1 \mathrm{~mm}$ short of the apex. The instruments were replaced by new ones every 5 roots.

All techniques were performed by a single operator. The work with one instrument was considered completed when file reached the working length, and there was no filling material covering the instrument. The smear layer was not removed after this step. The details for the instrumentation systems, used alone or combined are as follows.

\section{ProTaper universal retreatment}

D1-30/0.09 file was used for removal of filling material from the root canals in the coronal third, penetrating $5 \mathrm{~mm}$ in apical direction. D2-25/0.08 file was used until to middle third, penetrating $10 \mathrm{~mm}$. Finally, D3-20/0.07 file was used in the apical third, penetrating until the WL was reached. Manufacturer's recommendations were followed: progressive advancement in apical direction with in and out motion combined with brushing, small decreases of 1 to $2 \mathrm{~mm}$, frequent removal of the file to inspect it and removal of the propellers' debris before continuing.

\section{ProTaper universal}

The instruments S1-17/0.02-0.11 and S2-20/0.04-0.08-0.05 were used up to achieve the WL. After irrigation, F1-20/ 0.07-0.04 file was used to achieve the WL and the irrigation was performed again, followed by F2-25/0.08-0.04-0.03, F3-30/0.09-0.06-0.04-0.03 and F4-40/.06-.05-.04-.03 files, using the same criteria. The above recommendations were also followed.

\section{Mtwo retreatment}

Mtwo size 15/0.05 was used until the WL, followed by 25/0.05 file until the WL, both with lateral pressure. Manufacturer's recommendations were followed: frequent removal of the file to inspect it and removal of the propellers' debris before continuing.

\section{Mtwo}

Mtwo 10 file was introduced to achieve the WL and irrigation. Mtwo 15/0.05, 20/0.06, 25/0.06, 30/0.05, 35/ 0.04 and 40/0.04 were used in WL. The root canals were irrigated at each change of file. The same movement was used to ProTaper system.

\section{Evaluation}

When the reinstrumentation was finished, the roots were maintained 7 days, at $37^{\circ} \mathrm{C}$, for complete evaporation of the irrigant. For the later evaluation of exactly apical $5 \mathrm{~mm}$ (see below), the teeth were sectioned in $8 \mathrm{~mm}$ from the apex, approximately, perpendicular to the long axis, with a double-sided diamond disc, without refrigeration. The coronal portion of roots was discarded. After that, two longitudinal sections, centered on the proximal surfaces of the roots, were performed. A chisel was inserted into the grooves and the roots were split.

Photomicrographs were obtained from each apical hemisection (Leica DFC 290 camera HD; Leica Microsystems, Heerbrugg, St. Gallen, Switzerland) under a stereomicroscope at $\times 16$ magnification (Leica LED3000 NVI; Leica Microsystems, Heerbrugg, St. Gallen, Switzerland). The images were captured and analyzed using Leica Application Suite 3.6.0 software. It was selected the tool Region of Interest to restrict the analysis to the apical $5 \mathrm{~mm}$. Then, on the Acquire tab, it was defined 4 set points focus on Steps option. Finally, the Create Multifocus After Align Stack and the Acquire Images Before Combining were set to obtain a final combined image. The images were saved as TIFF format. The remaining filling material and the total canal area $\left(\mathrm{mm}^{2}\right)$ were measured in the final combined images in both apical hemisections, only in the last apical $5 \mathrm{~mm}$. A qualified examiner, blinded to the techniques used in the experiment, performed the measurements.

The clean area was calculated by subtracting the area containing the remaining filling material from the total canal area. The measurements of the clean area and the total canal area, for each hemisection, were added. With these data, the percentage of the clean area, considering the total canal area, was calculated. The measurements obtained for each NiTi rotary system were analyzed with the Kruskal-Wallis test. Statistical analyze was performed with SPSS version 17.0 (SPSS Inc, Chicago, IL, United States of America) with a confidence level set at $5 \%$.

\section{Results}

After filling removal and reinstrumentation, remaining filling material was found in all hemisections, regardless of the retreatment technique. The mean of the percentage of clean area was $54 \%$ considering the sixty instrumented teeth. The percentage of clean area was only higher than $50 \%$ in 34 teeth. The mean of the remaining filling area was $3.38 \mathrm{~mm}^{2}$ and the mean of the total canal area was $7.17 \mathrm{~mm}^{2}$. The root with less remaining filling material showed $0.40 \mathrm{~mm}^{2}$ ( $9 \%$ of the total area), while the highest amount found was $8.68 \mathrm{~mm}^{2}$ (79\% of the total area). Considering the total canal areas of all sixty teeth, the root canals did not vary significantly between the groups ( $\mathrm{p}=0.17$ ).

The techniques did not differ significantly $(p=0.09)$ in percentage of clean area. The mean of the percentage of clean area, median, minimum, maximum and standard deviation in each group are shown in Table 1.

\section{Discussion}

The maximum removal of gutta-percha and sealer followed by adequate reinstrumentation of root canals 
Table 1 Percentage of clean area: median, minimum, maximum and standard deviation in each group

\begin{tabular}{ccccccc}
\hline Group & Roots & Mean & Median & Minimum & Maximum & SD \\
\hline PTr & 15 & 63.20 & 69.65 & 25.29 & 90.97 & 17.75 \\
PT & 15 & 49.95 & 50.34 & 20.26 & 67.44 & 15.42 \\
M2r & 15 & 50.02 & 49.28 & 25.14 & 84.33 & 16.10 \\
M2 & 15 & 54.28 & 56.90 & 26.35 & 88.30 & 19.20 \\
\hline
\end{tabular}

are important to the success of endodontic retreatment. Thereby, the clinician has better access to remnants of necrotic tissue and microorganisms that are causing the persistence of periapical inflammation [9]. The present study, like many others [2,6,7,9-11], also verified that the removal of filling in all root canals were not complete. Furthermore, the percentage of clean area was much lower than expected, only $54 \%$.

The difference between the mean clean area percentages found in M2r and PTr groups were similar to those reported by Bramante et al. [2] in the evaluation of the apical third, and no statistically significant difference was found. These authors only compared retreatment instruments. In the present study, the difference between these groups was $13.18 \%(\mathrm{PTr}=63.20 \%$ and $\mathrm{M} 2 \mathrm{r}=50.02 \%)$ while in the aforementioned study was $14.90 \%(\mathrm{PTr}=47.30 \%$ and $\mathrm{M} 2 \mathrm{r}=32.40 \%)$. Certainly, the largest percentage of clean area found is justified by the fact that these groups were reinstrumented with both corresponding instrumentation systems up to $0.4 \mathrm{~mm}$ of diameter. Marfisi et al. [4] also found no significant difference when comparing both retreatment instruments, independently of the analyzed third. The difference between the percentage means to the clean area was very small, less than $1 \%(\mathrm{PTr}=76.30 \%$ and $\mathrm{M} 2 \mathrm{r}=75.67 \%$ ) in the CBCT analysis.

In the present study, the removal of filling material simultaneously to the instrumentation (PT and M2 groups) did not differ among themselves, but the group M2 left a smaller amount of remaining material compared to the PT group $\left(3.26 \mathrm{~mm}^{2}\right.$ and $4.14 \mathrm{~mm}^{2}$, respectively) considering the absolute values. This result contradicts the findings of Tasdemir et al. [7] who found that the PT system (final instrument, F3-30/0.09-0.05) showed significantly lower mean of remaining material compared to the M2 system (final instrument, F4-30/0.05).

Besides the D0 of the last instrument, the use of solvent and the irrigation were also standardized. The application of solvent during root canal retreatment is controversy. It is known that solvents have been used to facilitate the process, but these should be used with care given their cytotoxic potential and the possibility of forming a residual film of softened gutta-percha on the root canal walls $[12,13]$. Taking it into account, in the present study, the solvent was restricted to the coronal portion of the gutta-percha, just to facilitate the initial penetration on the gutta-percha and the volume was minimal. Differences in the volume of solvent or irrigant would certainly influence the cleaning during retreatment.

Following other studies [2,5,9-14] the present study used the percentage of clean area because this analysis takes into account the total area of the canals, a variable that certainly influences the quality of cleaning. Some studies, however, have measured only the amount of remaining material $[3,6,7,15]$. The method used for evaluation was the longitudinal cleavage and quantitative analysis with a stereomicroscope. This method allow a direct visualization of remaining filling material with magnification and it is a well established method in the literature $[1,9,16]$. Other common methods for this type of investigation are: radiographs [6,17], rendered transparent teeth $[7,15]$, CBCT $[4]$ and computed microtomography [10]. Among these, only mCT seems superior to the method employed by us. With radiographs and cleared teeth, the overlapping areas of remaining material are a common problem.

The question why the tested instruments sequences and many others of previous studies are unable to remove all remains of filling material needs to be addressed. The main reason for this occurrence lies in the fact that most endodontic instruments do not fit the root canal walls. Complementary procedures, as the use of Self Adjusting File or filing with Hedström files, have been employed to try solving this problem $[18,19]$. However, studies need to be conducted to develop a sequence or an instrument to optimizing the filling removal.

The design of this study was crucial to answer the question if retreatment instruments (Group PTr and M2r) are really necessary for the removal of filling material. It was evident that the instruments of two tested systems have similar performance to conventional $\mathrm{NiTi}$ rotary instrumentation systems (Group PT and M2), since there was no significant difference between tested groups. Furthermore, taking into account that in the present study, the number of instruments ranged 6 to 9 depending of the group, the number of instruments in a retreatment technique may not have great influence on gutta-percha removal. This is in agreement with a recent study that did not find statistical difference comparing two single file techniques with PTr in gutta-percha removal [13].

\section{Conclusions}

Considering the applied methodology, remaining filling material was found in all hemisections, regardless of the retreatment technique and PT or M2 were as effective as $\mathrm{PTr} / \mathrm{PT}$ or M2r/M2.

Competing interests

The authors declare that they have no competing interests. 


\section{Authors' contributions}

FRFA contributed supervising the study, writing and reviewing the manuscript. HPL designed the study. TOR was the specialist who performed the retreatment techniques and everything related to teeth operation. JOM performed the stereomicroscope analysis. All authors read and approved the final manuscript.

\section{Authors' information}

FRFA is PhD and Professor from Department of Endodontics, Faculty of Dentistry, Estácio de Sá University, Rio de Janeiro, RJ, Brazil. TOR is specialist in Endodontics and Postgraduate Student from Department of Endodontics, Faculty of Dentistry, Estácio de Sá University, Rio de Janeiro, RJ. JOM is Professor from Department of Endodontics, Santo Tomas University, Bucaramanga, Colombia. HPL is a Dr. and Professor from Department of Endodontics, Faculty of Dentistry, Estácio de Sá University, Rio de Janeiro, RJ, Brazil.

\section{Acknowledgments}

This study was supported by grants from Fundação Carlos Chagas Filho de Amparo à Pesquisa do Estado do Rio de Janeiro (FAPERJ), a Brazilian Governmental Institution.

\section{Author details}

'Department of Endodontics, Faculty of Dentistry, Estácio de Sá University, Av. Alfredo Baltazar da Silveira, 580/cobertura, Recreio dos Bandeirantes, Rio de Janeiro, RJ 22790-710, Brazil. ²Department of Endodontics, Santo Tomas University, Bucaramanga, Colombia.

Received: 9 June 2014 Accepted: 11 August 2014

Published: 15 August 2014

\section{References}

1. Giuliani V, Cocchetti R, Pagavino G: Efficacy of ProTaper universal retreatment files in removing filling materials during root canal retreatment. J Endod 2008, 34:1381-1384.

2. Bramante CM, Fidelis NS, Assumpcao TS, Bernardineli N, Garcia RB, Bramante AS, de Moraes IG: Heat release, time required, and cleaning ability of Mtwo $R$ and ProTaper universal retreatment systems in the removal of filling material. J Endod 2010, 36:1870-1873.

3. Somma F, Cammarota G, Plotino G, Grande NM, Pameijer CH: The effectiveness of manual and mechanical instrumentation for the retreatment of three different root canal filling materials. J Endod 2008, 34:466-469.

4. Marfisi K, Mercade M, Plotino G, Duran-Sindreu F, Bueno R, Roig M: Efficacy of three different rotary files to remove gutta-percha and resilon from root canals. Int Endod J 2010, 43:1022-1028

5. Saad AY, Al-Hadlaq SM, Al-Katheeri NH: Efficacy of two rotary NiTi instruments in the removal of Gutta-Percha during root canal retreatment. J Endod 2007, 33:38-41.

6. de Carvalho Maciel AC, Zaccaro Scelza MF: Efficacy of automated versus hand instrumentation during root canal retreatment: an ex vivo study. Int Endod J 2006, 39:779-784.

7. Tasdemir T, Er K, Yildirim T, Celik D: Efficacy of three rotary NiTi instruments in removing gutta-percha from root canals. Int Endod J 2008, 41:191-196.

8. Siqueira JF Jr, Rôças IN, Riche FN, Provenzano JC: Clinical outcome of the endodontic treatment of teeth with apical periodontitis using an antimicrobial protocol. Oral Surg Oral Med Oral Pathol Oral Radiol Endod 2008, 106:757-762

9. So MV, Saran C, Magro ML, Vier-Pelisser FV, Munhoz M: Efficacy of ProTaper retreatment system in root canals filled with gutta-percha and two endodontic sealers. J Endod 2008, 34:1223-1235.

10. Hammad M, Qualtrough A, Silikas N: Three-dimensional evaluation of effectiveness of hand and rotary instrumentation for retreatment of canals filled with different materials. J Endod 2008, 34:1370-1373.

11. Betti LV, Bramante CM, de Moraes IG, Bernardineli N, Garcia RB: Comparison of GPX with or without solvent and hand files in removing filling materials from root canals-an ex vivo study. Oral Surg Oral Med Oral Pathol Oral Radiol Endod 2010, 110:675-680.

12. Reddy N, Admala SR, Dinapadu S, Pasari S, Reddy MP, Rao MS: Comparative analysis of efficacy and cleaning ability of hand and rotary devices for gutta-percha removal in root canal retreatment: an in vitro study. J Contemp Dent Pract 2013, 14:635-643.
13. Rios MA, Villela AM, Cunha RS, Velasco RC, De Martin AS, Kato AS, Bueno CE: Efficacy of 2 reciprocating systems compared with a rotary retreatment system for gutta-percha removal. J Endod 2014, 40:543-546.

14. Takahashi CM, Cunha RS, de Martin AS, Fontana CE, Silveira CF, da Silveira Bueno CE: In vitro evaluation of the effectiveness of ProTaper universal rotary retreatment system for gutta-percha removal with or without a solvent. J Endod 2009, 35:1580-1583.

15. Schirrmeister JF, Wrbas KT, Meyer KM, Altenburger MJ, Hellwig E: Efficacy of different rotary instruments for gutta-percha removal in root canal retreatment. J Endod 2006, 32:469-472.

16. Tasdemir T, Yildirim T, Celik D: Comparative study of removal of current endodontic fillings. J Endod 2008, 34:326-329.

17. Masiero AV, Barletta FB: Effectiveness of different techniques for removing gutta-percha during retreatment. Int Endod J 2005, 38:2-7.

18. Abramovitz I, Relles-Bonar S, Baransi B, Kafir A: The effectiveness of a self-adjusting file to remove residual gutta-percha after retreatment with rotary files. Int Endod J 2012, 45:386-392.

19. Alves FRF, Vieira MVB, Moreno JO, Lopes WSP, Neves MAS, Siqueira JF Jr: Removal of filling material in the apical root canal by three retreatment approaches. ENDO (Lond Engl) 2012, 6:257-262.

doi:10.1186/1472-6831-14-102

Cite this article as: Alves et al.: Comparison of the efficacy of nickeltitanium rotary systems with or without the retreatment instruments in the removal of gutta-percha in the apical third. BMC Oral Health 2014 14:102.

\section{Submit your next manuscript to BioMed Central and take full advantage of:}

- Convenient online submission

- Thorough peer review

- No space constraints or color figure charges

- Immediate publication on acceptance

- Inclusion in PubMed, CAS, Scopus and Google Scholar

- Research which is freely available for redistribution

Submit your manuscript at www.biomedcentral.com/submit
C Biomed Central 